\title{
HETEROGENEOUS DATA TRANSFER AND LOADER
}

\author{
Ashwini Deshmukh ${ }^{1}$, Poonam Phalke ${ }^{2}$, Prasanna Gawande ${ }^{3}$, Shwetal Patil ${ }^{4}$ \\ ${ }^{1,2,3,4}$ Department of Information Technology, University of Pune, Marathwada Mitra Mandal's Institute of Technology, \\ Lohgaon, Pune-411047, India
}

\begin{abstract}
In early days information contain in increasingly corporate area, now IT organization help to right module to store, manage, retrieve and transfer information in the more reliable and powerful manner. As part of an Information Lifecycle Management (ILM) bestpractices strategy, organizations require solutions for migrating data between in heterogeneous environments and system storage. In early days information contain in increasingly corporate area, today IT organization help to right module to store, manage, retrieve and transfer information in the more reliable and powerful manner. This paper helps to planned to design powerful modules that high-performances data migration of storage area with less time complexity. This project contain unique information of data migration in dynamic IT nature and business advantage that design to provide new tool used for data migration.
\end{abstract}

Keywords - Heterogeneous Environment, data migration, data mapping

$* * *$

\section{INTRODUCTION}

When a company starts, it usually starts as a Small-Scale industry. And hence Microsoft Access Database is quite capable of handling its database and record with in it. But gradually as the company expands its database has to expand too. Thus they have to achieve more efficient database. The most widely used database is the Oracle Database. Hence this software, "Database Migrator" is aimed at making the conversion of an MS access database to Oracle database easy and efficient, without any effort and also need to technical knowledge.

A "Database Migrator" is usually developed for individuals and organizations to save time for converting to a new database if a database already developed. Instead of creating all the tables etc. of the already existing database, Migrating the database simply use software to covert sources database to destination database.

Database migration help to save time and easily converting huge database in heterogeneous environment

It can also be used by organizations that deal with complex data import, export and migration issues. After all, importing, exporting or migrating data between different sources is very complicated and time consuming, especially if these data sources store data in different formats or in heterogeneous environment. This is where a database migratory comes handy. The existing migrating tools available in the market are Oracle migration workbench and Swiss SQL.

\section{PURPOSE AND PROBLEM DEFINITION}

To develop migrating tool that helps in migrating database with its structure, data and relationship across various different database.

It will also provide technique migrating data from MS Access to SQL and Oracle.

The system will take an existing database in one format from the user and will convert it to a database in another format, which will be defined by the user.

An easy way to comply with the conference paper formatting requirements is to use this document as a template and simply type your text into it.

\section{OBJECTIVES}

To perform the database migration technique from MS Access to SQL server and MS Access to Oracle It will also perform SQL server to Oracle and vice versa.

In this scope following three areas describe that is restricted to migration perform systematically in normal database

- Migration perform source database to destination database.

- Second the follows migration of tables to the destination database.

- $\quad$ And the last steps actually perform migration of data from source to destination database.

- To prompt the user to select the source database and destination database. Connections for source and destination are tested. 
- Tree view structure is designed to enable the user to select and deselect tables, views for migration from source structure to the target structure.

- This form will display a summary of all the selected items. User is allowed to select constraints to be applied such as unique key ,primary key and foreign key .

- This form will display the status report after the migration is completed.

\section{LITERATURE SURVEY}

- In 1980 Appearances of this advancement, old systems have already been replaced by more effective system. During the process of updating, data migration is a significant issues. Data which are migrated in to new system not only are huge in size, but also are prerequisite for new system starting up vital basis of decision making[].

- In 2005 China information world propose by "Data migrate in three steps"[2].

1. Data migrated by tool beforehand

-This approach is adopted widely due to its high efficiency.

2. Data migrated manually by tool beforehand

-The cost \& error ratio of this approach are relatively high.

3. Data generated by new system afterwards

- In 2009 YANG Hai-Yan research of heterogeneous database conversion based on XMI, In this approach Consistency of the SQL syntax among related database $\&$ the complexity of SQL syntax, user may suffer from the poor usability[4].

\section{SYSTEM ARCHITECTURE}

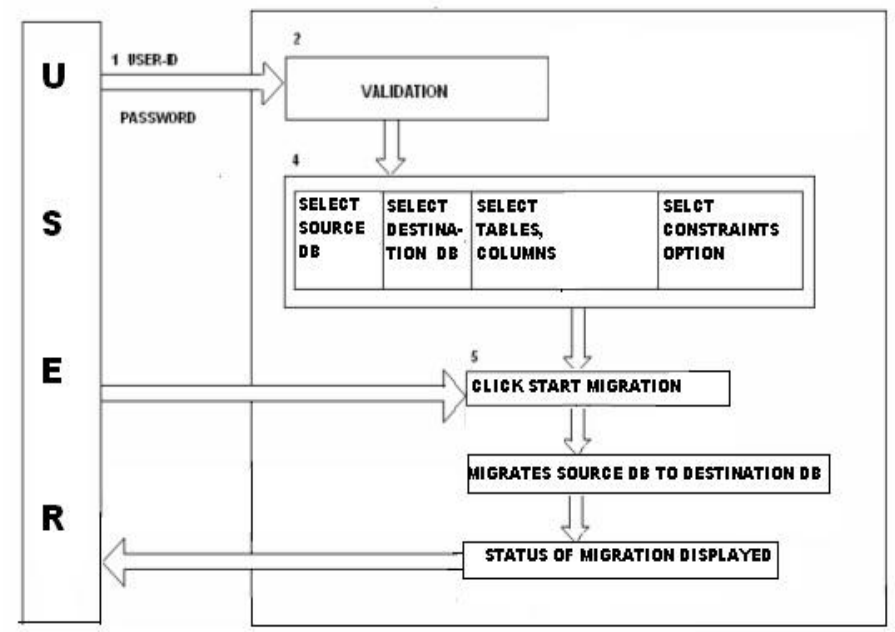

Fig. 1 System Architecture a. User is provided with the login facility and then user entered information is validated .

b. User will select the source database which is to be migrated.

c. After the connection is tested and then destination database will be selected.

d. The user will ask to select table name, structure of the table, constraints applied on it to be migrated.

e. Then migration will be start.

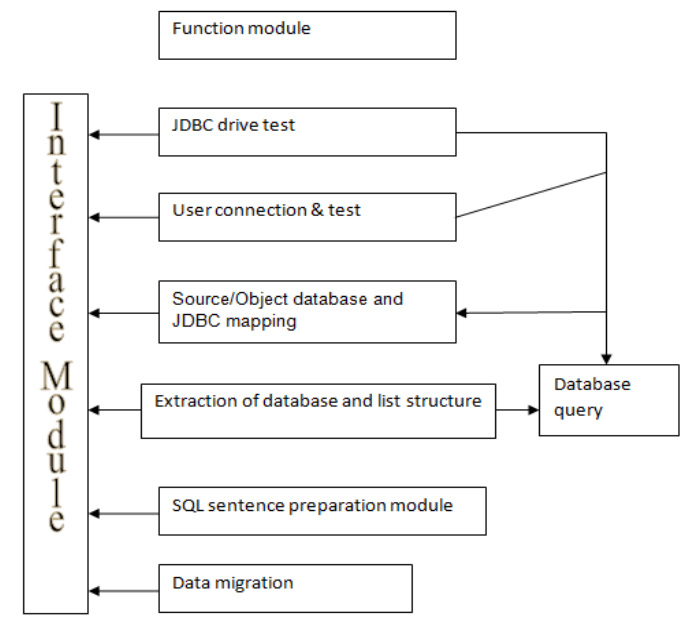

Fig. 2 Relationship between each data migration module

\section{DATA MIGRATION AND MAPPING}

Using data migration, If the result error rate exceeds the expectations, operation log should be examined. Most of errors can be solved by adjusting the mapping table and regulating database type compatible with Java.

Source object database type and JDBC mapping refers that the corresponding relationship between data type of database production and standard data type of JDBC interface, the purpose of which is to find a matched type in JDBC or a limit error in allowable range and finally meet users requirements. System embeds the data type mapping table to match the data type of JDBC with the one of the GBase, Oracle, Microsoft SQL server 2000,DB2 and MySQL. JDBC data types can be classified in to numeric, character, big object, date and special.

\section{QUERY EXTRACTION OF DATABASE STRUCTURE}

The extraction of database structure is to load the source database pattern and table structure information into the middle database, then generate SQL sentence of the source database . the information of the middle database is used to create migration sentence. Extraction adopts preorder traversal method to load source database information into the middle database. 


\section{DATABASE QUERY}

The model provide user with standard database information of active connection, database pattern and table information.; field information of the table, sentence that generates the table and the data within; mapping relationship between database data and JDBC, sending and implementing query operation in database by importing SQL sentences.

The function of this module is similar to simplified data browser and database query. All related action logic is control by interface module. Background provides only related parameters, initial and synchronization operations.

\section{CONCLUSIONS}

We adapted the incremental scheme to the data migration in the multi database system. By experimental result ,our incremental scheme is effective for the improvement of execution time.

For future work, we need to evaluate the performances of our scheme in more real solution. If including units in the label, present them within parentheses. Do not label axes only with units. In the example,

\section{ACKNOWLEDGMENTS}

We take this opportunity to thank our project guide Prof. Mrs. Shweta IPatil and Head of the Department Prof. Mr. Wagh K.S. for their valuable guidance and for providing all the necessary facilities, which were indispensable in the completion of this project report. We are also thankful to all the staff members of the Department of Information technology of MarathwadaMitraMandal Institute of Technology, Pune for their valuable time, support, comments, suggestions and persuasion. We would also like to thank the institute for providing the required facilities, Internet access and important books.

\section{REFERENCES}

[1] Omiecinski, E., Concurrent File Reorganization: Clustering, Conversion and MaintenNance, Data Engineering Bulletin,19,2,pp 25-32,1996.

[2] Xia Kai, "'Data migrate in three steps"', China information world, vol. 17 January 2005.

[3] Chen Huaying, "'Data move online-data migration and its applications"', PC WORLD CHINA,2008,pp.72-76.

[4] YANG Hai-yan, Research of Heterogeneous Database Conversion Based on XMI, Computer Knowledge and Technology, vol. 12,2009.

[5] Pan Yi,Study on the Synchronization Problems for Isomerous Database, O_ce Information, vol. 12,2009.

[6] www.mysql.com

[7] Higuchi,, K. and Tsuji, T., On-line Reorganization for Distributed Index system for complex Objects, IPSJ Trans. of Database, 45,SIG10(TOD23) ,pp 1-17,2004.
[8] Li Wei, Cai Yingwei, Xu Hui, "Desing And Implementation of Integrated platform of Heterogeneous Database based on Multithreding "Modern Electronic Power, Vol.25(5),pp.69-72, October2008. 